\author{
( ${ }^{a}$ 武汉大学 化学与分子科学学院 武汉 430072)
} \\ 黄菊 $a$ 李贞 $*, b \quad$ 刘志洪 $*, a, b$ \\ ( $b$ 湖北大学 化学化工学院 武汉 430062)
}

近红外光激发功能化上转换纳米颗粒用于解聚 $A \beta$ 聚集体

\begin{abstract}
摘要 阿尔兹海默症 $(\mathrm{AD})$ 是一种进行性神经退行性疾病, 其特征是记忆力减退、神志不清和各种认知障碍. $\beta$-淀粉样蛋 白 $(\mathrm{A} \beta)$ 的自组装聚集是阿尔茨海默症患者大脑的主要特征之一, 其加剧了 $\mathrm{AD}$ 患者的神经病变和认知障碍, 因此抑制 $A \beta$ 聚集是一种潜在的治疗 $A D$ 的策略. 光动力疗法是抑制 $A \beta$ 聚集和解聚 $A \beta$ 聚集体的有效方法. 然而, 大多数光敏剂 为紫外和可见光激发, 在生物组织中的渗透深度低, 并引起严重的组织损伤, 这限制了其在生物医学中的应用. 本工 作构建了一种近红外光激发的双靶向上转换纳米体系应用于抑制 $\mathrm{A} \beta$ 聚集过程. 以核壳结构的上转换纳米颗粒(UCNPs) 作为光转换器, 通过两亲聚合物二硬脂酰基磷脂酰乙醇胺-聚乙二醇-马来酰亚胺(DSPE-PEG-MAL)的疏水包覆作用负 载光敏剂二氢卟吩 $\mathrm{e} 6(\mathrm{Ce})$ ), 在纳米颗粒表面通过马来酰亚胺与統基的特异性反应修饰了可跨越血脑屏障的肽链 TGN 和靶向 $\mathrm{A} \beta_{42}$ 的肽链 $\mathrm{QSH}$. 实验结果表明在近红外光激发下 UCNPs 通过发光共振能量转移(LRET)将能量转移至光敏剂 $\mathrm{Ce} 6$, 使其跃迁至激发态后与周围的氧气分子作用产生单线态氧 $\left({ }^{1} \mathrm{O}_{2}\right)$, 不可逆地氧化 $\mathrm{A} \beta$, 从而有效解聚了 $\mathrm{A} \beta$ 聚集体, 降低了 $\mathrm{A} \beta$ 聚集体的神经毒性. 此外, 该体系不仅具有良好的生物相容性, 而且可以有效穿过血脑屏障靶向作用于 $\mathrm{A} \beta_{42}$ ，显示出其在活体水平治疗 $\mathrm{AD}$ 的潜力.
\end{abstract}

关键词 近红外光; 上转换纳米颗粒; 光动力治疗; $\beta$-淀粉样蛋白; 阿尔兹海默症

\section{Functionalized Upconversion Nanoparticles for Disassembly of $\beta$-Amyloid Aggregation with Near-Infrared Excitation}

\author{
Ju Huang ${ }^{a} \quad$ Zhen $\mathrm{Li}^{*}, b \quad$ Zhihong Liu*,a,b \\ $\left({ }^{a}\right.$ College of Chemistry and Molecular Sciences, Wuhan University, Wuhan 430072, China) \\ ( ${ }^{b}$ College of Chemistry and Chemical Engineering, Hubei University, Wuhan 430062, China)
}

\begin{abstract}
Alzheimer's disease (AD) is a progressive neurodegenerative disorder characterized by memory loss, confusion, and a variety of cognitive disabilities. The self-assembly and aggregation of $\beta$-amyloid $(A \beta)$ peptides is a main feature of the brain of Alzheimer's disease, which can aggravate the nerve damage and cognitive impairment of AD patients. Therefore, inhibition of the aggregation of $\mathrm{A} \beta$ peptides is recognized as a potential strategy to alleviate $\mathrm{AD}$. Photodynamic therapy (PDT) is a creative method that has wide applications in suppressing amyloid aggregation or eliminating the amyloid aggregates. However, most photosensitizers are excited by ultraviolet and visible light, have a low penetration depth in biological tissues, and cause serious tissue damage, which limits their application in biomedicine. Herein, we report a dual-targeting upconversion nanoprobe excited by near-infrared light to inhibit the A $\beta$ aggregation process. The core-shell structured upconversion nanoparticles $\mathrm{NaYF}_{4}: \mathrm{Yb}, \mathrm{Er}, \mathrm{Gd}, \mathrm{Tm} @ \mathrm{NaYF}_{4}$ are used as light converters, and the photosensitizer chlorin-e6 (Ce6) is loaded through the hydrophobic coating of the amphiphilic polymer 1,2-distearoylsn-glycero-3-phosphoethanolamine- $N$ [maleimide(polyethyleneglycol)-2000] (DSPE-PEG-MAL). A blood-brain barrier targeting peptide, TGN, and a A $\beta$ target peptide, QSH, are simultaneously modified on the surface of nanoparticles via the specific reaction between maleimide and sulfhydryl groups. The results indicate that UCNPs can transfer the excited-state energy to the photosensitizer Ce6 through luminescence resonance energy transfer (LRET) process under the excitation of near-infrared light irradiation. After transition to the excited state, $\mathrm{Ce} 6$ further interact with the surrounding oxygen molecules to produce singlet oxygen $\left({ }^{1} \mathrm{O}_{2}\right)$ and irreversibly oxidize $\beta$-amyloid, thus effectively disassembling $A \beta$ aggregates and reducing the cytotoxicity associated with $A \beta$. In addition, UCNPs-Ce6-TQ not only exhibits good biocompatibility, but also can effectively cross the blood-brain barrier and target $A \beta_{42}$. This nanoprobe may be a powerful tool to inhibit the accumulation of $A \beta$ in the brain and alleviate the neurotoxic damage caused by $A \beta$.

Keywords near infrared; upconversion nanoparticles; photodynamic therapy; beta-amyloid; Alzheimer's disease
\end{abstract}

* E-mail: zhenli@hubu.edu.cn; zhhliu@whu.edu.cn

Received May 6, 2021; published June 8, 2021.

Supporting information for this article is available free of charge via the Internet at http://sioc-journal.cn.

Project supported by the National Natural Science Foundation of China (Nos. 21807028, 21625503).

项目受国家自然科学基金(Nos. 21807028, 21625503)资助. 


\section{1 引言}

随着人口老龄化的加剧, 阿尔兹海默症 (Alzheimer's disease, AD) 的发病率不断上升, AD 患者的数 量呈现指数增长, 预计到 2050 年, 全球 $\mathrm{AD}$ 患者人数将

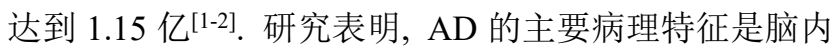
$\beta$-淀粉样蛋白 $(\beta$-amyloid, $A \beta)$ 在神经元外聚集沉积, 从 而加剧了 $\mathrm{AD}$ 患者的神经病变和认知障碍 ${ }^{[3-5]}$. $\mathrm{A} \beta$ 肽是 $\beta-$ 分泌酶和 $\gamma$-分泌酶对淀粉样前体蛋白(amyloid precursor protein, APP)进行切割所得, 最常见的 $A \beta$ 有 $A \beta_{40}$ 和 $\mathrm{A} \beta_{42}, \mathrm{~A} \beta_{42}$ 更容易自组装形成富含 $\beta$-折叠的聚集体 ${ }^{[6-8]}$. 起初, 研究人员认为 $A \beta$ 相关的毒性起源于成熟的淀粉 样蛋白斑块, 但最新研究结果表明 $\mathrm{A} \beta$ 聚集过程中早期 形成的可溶性寡聚体 $A \beta$ 会引起更大的神经元损伤 ${ }^{[9-10]}$. 因此, 抑制 $\mathrm{A} \beta$ 聚集过程和降解 $\mathrm{A} \beta$ 聚集体是治疗 $\mathrm{AD}$ 的 有效策略之一. 目前为止已经报道了多种药物, 包括小

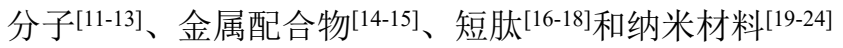
等可以阻止 $\mathrm{A} \beta$ 聚集, 破坏纤维稳定性. 但是, 这些药物 具有对 $A \beta$ 位点选择性差、靶向性低和穿过血脑屏障能 力弱等缺点, 因此限制了其对 $A \beta$ 聚集的有效抑制和对 成熟 $A \beta$ 原纤维的解聚能力 ${ }^{[25-26]}$.

光动力疗法(photodynamic therapy, PDT) 由于具有 时空可控和微创的特点, 被广泛应用于皮肤癌、乳腺癌 和胰腺癌等疾病的治疗 ${ }^{[27-28]}$. 近年来, PDT 已成为抑制 $A \beta$ 聚集和降解 $A \beta$ 聚集体的有效策略 ${ }^{[29-30]}$. 光动力治疗
过程中，在特定波长光照下光敏剂会产生活性氧 (reactive oxygen species, ROS), 将 $\mathrm{A} \beta$ 肽链上的甲硫氨 酸(methionine, Met)和组氨酸(histidine, His)氧化, 增加 了 $\mathrm{A} \beta$ 表面的亲水性, 降低了 $\mathrm{A} \beta$ 肽自组装成富含 $\beta$-折叠 聚集体的倾向 ${ }^{[12]}$. 但是在 PDT 中, 大多数光敏剂为紫外 可见光激发, 存在生物组织穿透深度低, 组织损伤严重 等局限性. 相比之下, 近红外光(near infrared light, NIR) 显示出更高的组织穿透深度和较小的光损伤作用 [31-33]. 镧系元素离子掺杂的上转换纳米颗粒 (upconversion nanoparticles, UCNPs) 具有近红外光激发、反斯托克斯发 射、光稳定性好、信噪比高、苂光寿命长、避免自发荧

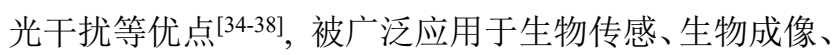
光动力治疗和光热治疗等生物医学相关领域 [39-44]. 因 此, UCNPs 是一类理想的光转换材料, 能有效克服传统 光敏剂组织穿透深度浅、光损伤严重的局限性, 用于深 层组织的光动力治疗体系.

本工作构建了一种近红外光激发的双靶向上转换 纳米体系来抑制 $A \beta$ 聚集过程，从而缓解 $A \beta$ 诱导的神经 毒性作用. 该体系的构建方法如图 1 所示, 以核壳结构 的上转换纳米颗粒 $\mathrm{NaYF}_{4}: \mathrm{Yb}, \mathrm{Er}, \mathrm{Gd}, \mathrm{Tm} @ \mathrm{NaYF}_{4}$ 作为光 转换器, 通过两亲聚合物二硬脂酰基磷脂酰乙醇胺聚乙二醇-马来酰亚胺(DSPE-PEG-MAL)的疏水包覆作 用与光敏剂二氢卟吩 e6 (chlorin-e6, Ce6)组装, 形成 UCNPs-Ce6. 其次为了更有效地抑制 $\mathrm{A} \beta$ 聚集, 我们在 纳米颗粒表面通过马来酰亚胺与颈基的特异性反应修

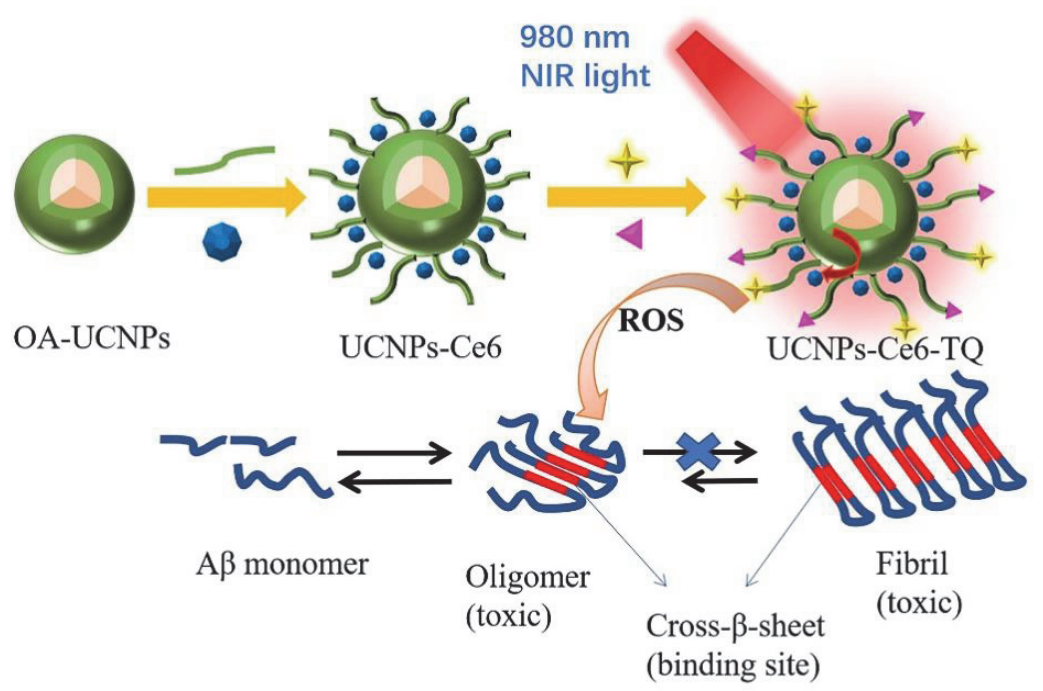

Inhibition of $A \beta$ aggregation

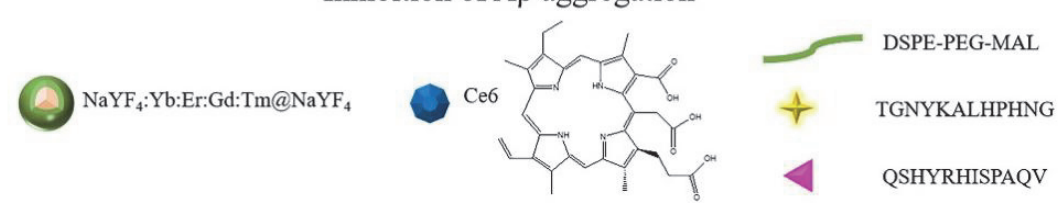

图 1 基于双靶向负载光敏剂的上转换纳米体系在近红外光激发下抑制 $\mathrm{A} \beta$ 聚集的机理图. 在近红外光 $(980 \mathrm{~nm})$ 照射下, 上转换纳米颗粒发射 655 $\mathrm{nm}$ 可见光从而激发光敏剂 $\mathrm{Ce} 6$ 产生单线态氧 $\left({ }^{1} \mathrm{O}_{2}\right)$ 不可逆地氧化了 $\mathrm{A} \beta$, 从而有效解聚 $\mathrm{A} \beta$ 聚集体

Figure 1 The mechanism diagram of the upconversion nanoparticles with dual-targeting and loaded photosensitizer to inhibit $A \beta$ aggregation under near-infrared light irradiation. Under near-infrared light $(980 \mathrm{~nm})$ excitation, the upconversion nanoparticles emit $655 \mathrm{~nm}$ visible light to excite the photosensitizer $\mathrm{Ce} 6$ to produce singlet oxygen $\left({ }^{1} \mathrm{O}_{2}\right)$ to irreversibly oxidize $\mathrm{A} \beta$ peptides, thereby effectively disassembling $\mathrm{A} \beta$ aggregates 
饰了两种配体来实现双靶向作用, 得到 UCNPs-Ce6-TQ. 基于多肽类靶向分子易于合成、免疫原性低、竞争结合 作用不明显及受体内环境干扰小的优点 ${ }^{[45]}$, 因此, 我们 首先选择具有十二个氨基酸的 TGN (TGNYKALHPHNG) 多肽作为将纳米体系转运到大脑 的第一阶段配体, TGN 肽链靶向血脑屏障(blood brain barrier, BBB)增加纳米颗粒的 BBB 渗透性, 促进在脑中 的积累 ${ }^{[46-47]}$. 其次, 我们选择 QSH (QSHYRHISPQV)多 肽作为二级靶向配体, 其可在亚微摩尔范围内与 $\mathrm{A} \beta_{42}$ 部分位点结合, 对 $\mathrm{A} \beta_{42}$ 具有较强特异性, 促使纳米颗粒 富集于 $\mathrm{A} \beta_{42}$ 部位 ${ }^{[48-50]}$. 在该体系中, 上转换纳米颗粒捕 获近红外激发光的能量后, 将该能量通过发光共振能量 转移(luminescence resonance energy transfer, LRET)的模 式传递至光敏剂 $\mathrm{Ce} 6$, 使其跃迁至激发态后与周围的氧 气分子作用产生单线态氧( singlet oxygen, ${ }^{1} \mathrm{O}_{2}$ ) 氧化 $\mathrm{A} \beta$, 从而解聚 $\mathrm{A} \beta$ 聚集体, 削弱其神经毒性, 达到治疗效果.

\section{2 结果与讨论}

\section{1 实验设计原理}

为了缓解 $\mathrm{A} \beta$ 诱导的神经毒性, 本工作提出利用 UCNPs 介导的 PDT 来调节 A $\beta$ 的聚集过程. 如图 1 所示, 我们选择以 $980 \mathrm{~nm}$ 激发, $655 \mathrm{~nm}$ 发射的 $\mathrm{NaYF}_{4}: \mathrm{Yb}, \mathrm{Er}$, $\mathrm{Gd}, \mathrm{Tm} @ \mathrm{NaYF}_{4}$ 作为 UCNPs 的基本结构. 其近红外光激 发的特点, 可有效提高 PDT 作用的组织穿透深度, 降低 对组织的光损伤. 其次, 由于光敏剂 Ce6 的吸收光谱与 UCNPs 在 $655 \mathrm{~nm}$ 的发射光谱相匹配, 因此可以通过 LRET 的方式接收来自 UCNPs 的能量从而到达光敏剂 的激发态，随后处于激发态的光敏剂把该能量传递给周 围的氧气分子, 产生活性较高的单线态氧, 氧化 $\mathrm{A} \beta$, 抑 制 $\mathrm{A} \beta$ 聚集过程, 从而缓解 $\mathrm{A} \beta$ 聚集体的神经毒性. 最后, 我们在材料的表面分别修饰了可跨越血脑屏障的肽链 $\mathrm{TGN}$ 和靶向 $\mathrm{A} \beta_{42}$ 的肽链 $\mathrm{QSH}$, 赋子了该材料穿透血脑 屏障并在 $A \beta_{42}$ 处的有效富集的能力.

\section{2 油酸修饰上转换纳米颗粒(OA-UCNPs)的表征}

我们通过逐层晶种生长法合成了核壳结构的 UCNPs $\left(\mathrm{NaYF}_{4}: 20 \% \mathrm{Yb}, 2 \% \mathrm{Er}, 10 \% \mathrm{Gd}, 0.2 \% \mathrm{Tm} @ \mathrm{NaYF}_{4}\right)$. 其中, 掺杂的 $\mathrm{Gd}^{3+}$ 用于控制晶核生长, 合成适当尺寸的 纳米颗粒. $\mathrm{Er}^{3+}$ 和 $\mathrm{Tm}^{3+}$ 作为发光离子, 用于调控材料在 $655 \mathrm{~nm}\left({ }^{4} \mathrm{~F}_{9 / 2} \rightarrow{ }^{4} \mathrm{I}_{15 / 2}\right)$ 和 $800 \mathrm{~nm}\left({ }^{3} \mathrm{H}_{4} \rightarrow{ }^{3} \mathrm{H}_{6}\right)$ 发射较强的荧 光, 最后包覆一层惰性壳 $\mathrm{NaYF}_{4}$ 以减少表面猝灭, 进而 提高上转换发光强度. 利用透射电子显微镜 (transmission electron microscope, TEM) 对合成的核-壳结构 UCNPs 进行形貌与粒径分析. 如图 2 所示, 上转换纳米 颗粒为粒径均一的球形颗粒, 统计分析得到核纳米颗粒 的粒径为 $(21.35 \pm 1.70) \mathrm{nm}$, 核壳纳米颗粒平均粒径为 $(25.38 \pm 1.32) \mathrm{nm}$. 对 UCNPs 进行高分辨透射电镜 (high resolution transmission electron microscope,
HRTEM)和 X-射线粉末衍射(X-ray powder diffraction, $\mathrm{XRD}$ )物相分析(如图 S1a, S1b). 高分辨透射电镜图中可 清晰看到 UCNPs 为球形颗粒, 经过物相检索并与 $\beta-\mathrm{NaYF}_{4}$ 的标准物相卡片(JCPDS No. 16-0334)相比较, 显示出所合成的 UCNPs 为六方相, 相比于立方相结构纳 米颗粒具有更高的上转换发光效率. 高角环形暗场成像 (high- angle annular dark-field imaging, HAADF)和 F, Gd, $\mathrm{Yb}, \mathrm{Er}$ 以及 $\mathrm{Tm}$ 元素的分布谱图证明所得到的上转换纳 米颗粒的结构组成与所设计的核壳结构一致(如图 S1c).

\subsection{UCNPs-Ce6-TQ 体系的构建及表征}

两亲聚合物 DSPE-PEG-MAL 通过疏水-疏水相互作 用包覆 OA-UCNPs, 使 UCNPs 具有水溶性和生物相容 性. 将光敏剂 Ce6 负载于 UCNPs 表面和 PEG 层之间的 疏水腔中以形成 UCNPs-Ce6. 由于光敏剂 Ce6 的吸收光 谱与 UCNPs 在 $655 \mathrm{~nm}$ 的发射光谱相匹配(图 3a), 可以 作为 LRET 过程中 UCNPs 的能量受体, UCNPs 在 655 $\mathrm{nm}$ 的上转换发光因为表面光敏剂 Ce6 的负载而下降(图 3b). $1 \mathrm{mg} / \mathrm{mL}$ UCNPs 与不同浓度的 Ce6 混合, 通过离心 将未负载的 Ce6 除去, UCNPs-Ce6 的紫外吸收光谱如图 $3 \mathrm{c}$ 所示, $\mathrm{Ce} 6$ 的负载量随着加入 $\mathrm{Ce} 6$ 浓度的升高而增加, Ce6 的负载量最大达到 $92 \mu \mathrm{g} / \mathrm{mg} \operatorname{UCNPs}($ 图 S2). UCNPs-Ce6 位于 $655 \mathrm{~nm}$ 处的红光发射强度随加入 Ce6 的浓度增加不断降低, 当 $1 \mathrm{mg} / \mathrm{mL}$ UCNPs 负载 90 $\mu \mathrm{g} / \mathrm{mL}$ 的 $\mathrm{Ce} 6$ 时的猝灭效率达到平台, 计算为 $83.34 \%$ (如图 S3 所示).

通过 TGN (TGNYKALHOHNGC) 和 QSH ( Q S H Y R H I S P Q V C) 末端半胱氨酸上的颈基和 $\mathrm{UCNPs}-\mathrm{Ce} 6$ 表面的马来酰亚胺反应相连得到 UCNPs-Ce6-TQ(图 S4). 为了准确定量修饰在纳米颗粒 上两条肽链的浓度, 分别使用异硫氰酸苂光素(FITC)标 记的 TGN 和 5-羧基四甲基罗丹明(TAMRA)标记的 QSH 来替代 TGN 和 QSH. 如图 3d 所示, 将 UCNPs-Ce6-TQ 的紫外吸收图与 FITC-TGN 和 TAMRA-QSH 的紫外吸 收对比可得, UCNPs-Ce6-TQ 中 FITC 染料紫外吸收红移 至 $502 \mathrm{~nm}$, TAMRA 染料紫外吸收峰值仍在 $557 \mathrm{~nm}$, 证 明 UCNPs-Ce6-TQ 组装成功. 根据不同浓度下 FITC-TGN 和 TAMRA-QSH 分别在 $477 \mathrm{~nm}$ 和 $557 \mathrm{~nm}$ 处 的紫外吸光度做出标准曲线(图 S5), 测量离心后上清溶 液中 FITC-TGN 和 TAMRA-QSH 吸光度, 计算得到 UCNPs-Ce6-TQ 表面标记的 TGN 为 $0.19 \mathrm{mg} / \mathrm{mg}$ UCNPs 和 QSH 为 $0.09 \mathrm{mg} / \mathrm{mg}$ UCNPs. TEM 表明 UCNPs-PEG 在负载光敏剂并修饰靶向肽链后, 其形貌未发现明显变 化(图 S6). 动态光散射(dynamic light scattering, DLS)表 征显示, UCNPs-PEG 的水合动力学直径为 $58.77 \mathrm{~nm}$ (图 $\mathrm{S} 7 \mathrm{a}), \mathrm{UCNPs}$ 负载光敏剂 Ce6 之后, UCNPs-Ce6 水合动 力学直径增大至 $78.82 \mathrm{~nm}$ (图 S7b), UCNPs-Ce6 修饰上 $\mathrm{TGN}$ 和 $\mathrm{QSH}$ 肽后, 水合动力学直径最终达到 91.28 
$\mathrm{nm}$ (图 S7c). 测得的 UCNP-Ce6 和 UCNP-Ce6-TQ 纳米 颗粒的 zeta 电势分别为 $-26.43 \mathrm{mV}$ 和 $-22.97 \mathrm{mV}$ (图 S7d). 另外, 构建的 UCNPs-Ce6-TQ 具有良好的光稳定

(a)

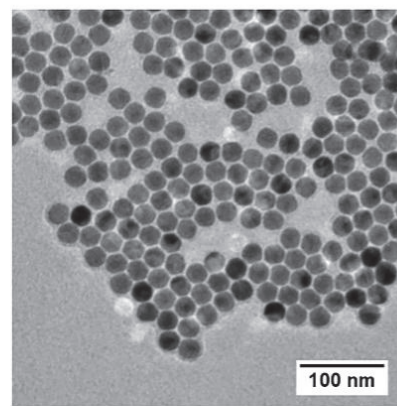

(c)

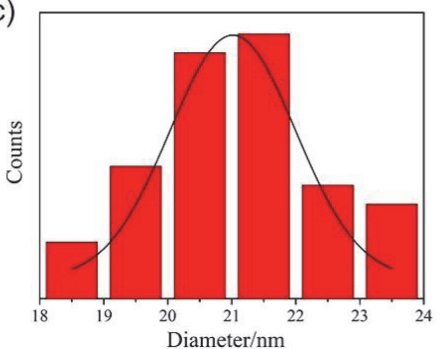

性和热力学稳定性, 在 $980 \mathrm{~nm}$ 连续光照 $60 \mathrm{~min}$, 上转换 苂光强度维持不变(图 $\mathrm{S} 8 \mathrm{a})$; 在 $37^{\circ} \mathrm{C}$ 下孵育 $120 \mathrm{~min}$, 上转换荧光强度也无明显变化(图 S8b).

(b)

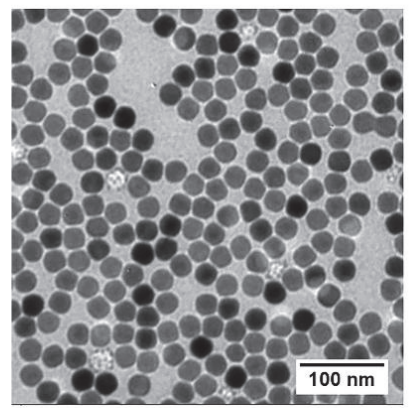

(d)

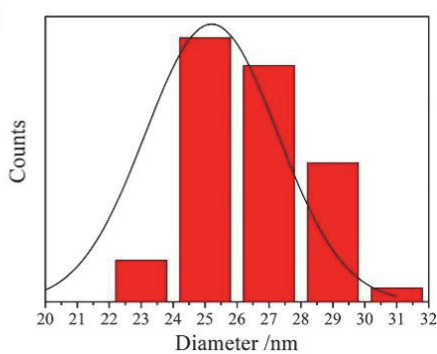

图 2 (a) $\mathrm{NaYF}_{4}: \mathrm{Yb}, \mathrm{Er}, \mathrm{Gd}, \mathrm{Tm}$ 和(b) $\mathrm{NaYF}_{4}: \mathrm{Yb}, \mathrm{Er}, \mathrm{Gd}, \mathrm{Tm} @ \mathrm{NaYF}_{4}$ 纳米颗粒的透射电镜图. (c) $\mathrm{NaYF}_{4}: \mathrm{Yb}, \mathrm{Er}, \mathrm{Gd}, \mathrm{Tm}$ 和(d) $\mathrm{NaYF}$ : $\mathrm{Yb}, \mathrm{Er}, \mathrm{Gd}, \mathrm{Tm} @$ $\mathrm{NaYF}_{4}$ 的粒径分布图

Figure 2 Transmission electron microscope images of (a) $\mathrm{NaYF}_{4}: \mathrm{Yb}, \mathrm{Er}, \mathrm{Gd}, \mathrm{Tm}$ and (b) $\mathrm{NaYF}_{4}: \mathrm{Yb}, \mathrm{Er}, \mathrm{Gd}, \mathrm{Tm} @ \mathrm{NaYF}_{4}$. Histograms of the size distribution of (c) $\mathrm{NaYF}_{4}: \mathrm{Yb}, \mathrm{Er}, \mathrm{Gd}, \mathrm{Tm}$ and (d) $\mathrm{NaYF}_{4}: \mathrm{Yb}, \mathrm{Er}, \mathrm{Gd}, \mathrm{Tm} @ \mathrm{NaYF}_{4}$
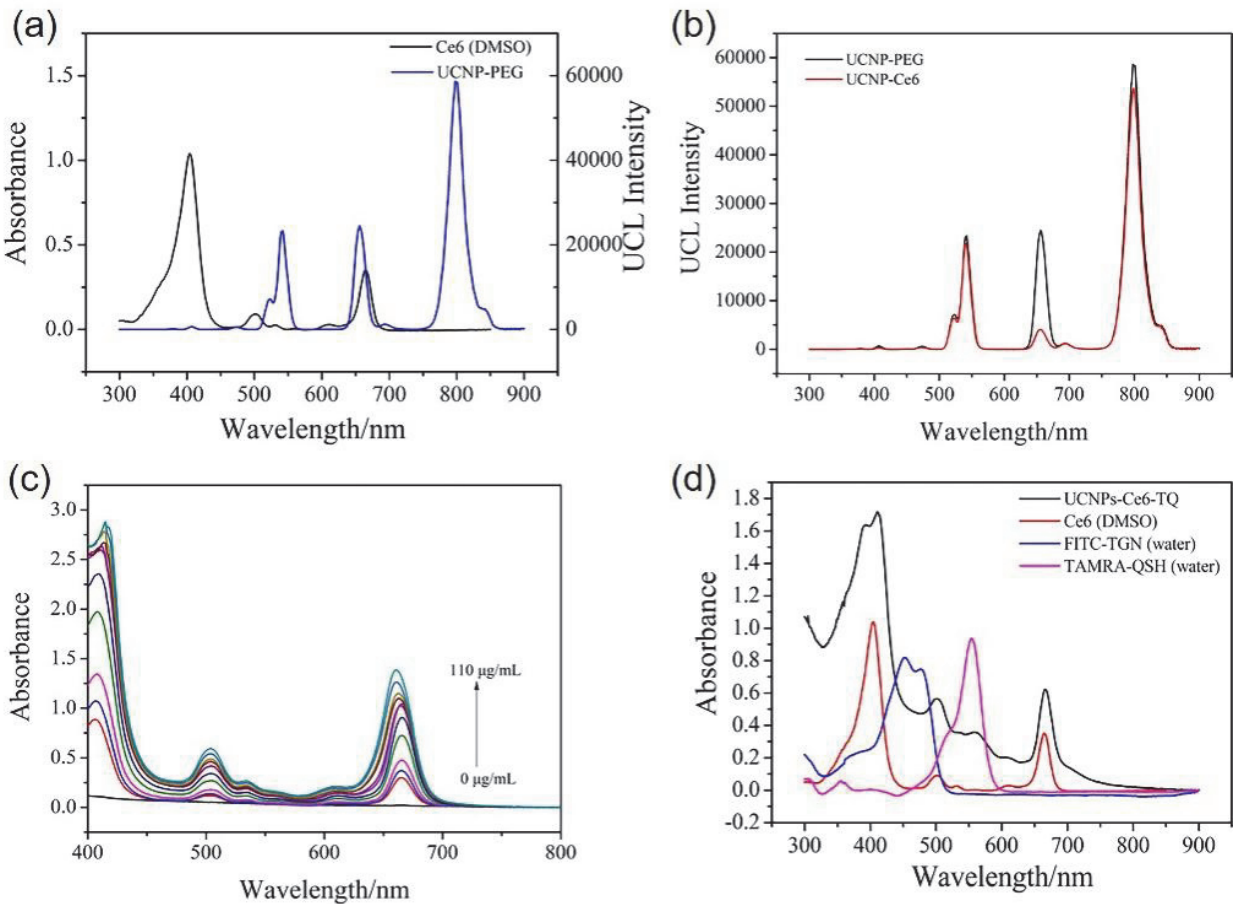

图 3 (a) 光敏剂 Ce6 的紫外吸收谱图与水相 UCNPs-PEG 在近红外光照下上转换发光谱图重叠. (b) UCNPs 负载光敏剂 Ce6 前后上转换发光光谱. (c) 负载不同浓度 Ce6 (0 110 $\mu \mathrm{g} / \mathrm{mL})$ 的 UCNPs (1 mg/mL) 的 UV-vis 吸收光谱. (d) UCNPs-Ce6-TQ 的紫外吸收图与光敏剂以及染料标记的两条肽 链的紫外吸收对比

Figure 3 (a) The UV absorption spectrum of the photosensitizer Ce6 overlaps with the upconversion emission spectrum of UCNPs-PEG in aqueous under near-infrared light excitation. (b) The upconversion luminescence spectra of UCNPs before and after loading the photosensitizer Ce6. (c) UV-vis absorbance spectra of UCNPs $(1 \mathrm{mg} / \mathrm{mL})$ loaded with different concentrations $(0 \sim 110 \mu \mathrm{g} / \mathrm{mL})$ of Ce6. (d) Comparison between the UV-vis absorption spectra of UCNPs-Ce6-TQ, photosensitizer and the two peptide chains labeled with the dyes 


\subsection{UCNP-Ce6-TQ 产生活性氧性能研究}

我们利用商品化探针 9,10-蒽基-双(亚甲基)二丙二 酸(ABDA)评估 UCNPs-Ce6-TQ 产生单线态氧 $\left({ }^{1} \mathrm{O}_{2}\right)$ 的能 力. $\mathrm{ABDA}$ 与 ${ }^{1} \mathrm{O}_{2}$ 的反应产生含有过氧桥环的中间体, 破 坏了 $\mathrm{ABDA}$ 的共轭体系, 使得其 $435 \mathrm{~nm}$ 的苂光强度减 弱. 如图 S9 所示, ABDA 水溶液在 $980 \mathrm{~nm}$ 功率为 0.76 $\mathrm{W} / \mathrm{cm}^{2}$ 激光照射后荧光强度保持不变, 说明单独的近红 外光照条件对 $\mathrm{ABDA}$ 的苂光没有影响. 而当 $\mathrm{ABDA}$ 与 UCNPs-Ce6-TQ 共同孵育再经近红外光照处理后, ABDA 的苂光强度显著降低, 说明我们所构建的纳米体 系确实可以有效地产生活性氧(图 S10). 比较负载不同 浓度光敏剂的体系 UCNPs-45Ce6-TQ(Ce6 负载量为 45 $\mu \mathrm{g} / \mathrm{mg}$ UCNPs) 和 UCNPs-90Ce6-TQ 组(Ce6 负载量为 90 $\mu \mathrm{g} / \mathrm{mg}$ UCNPs)(图 S11) 可得, UCNPs-90Ce6-TQ 组的 ABDA 苂光强度随光照时间快速下降, 在近红外光照射 $30 \mathrm{~min}$ 后 $\mathrm{ABDA}$ 苂光强度可下降 55\%左右. 结果表明光

动力产生活性氧的能力依赖于负载光敏剂的浓度, UCNPs-90Ce6-TQ 能够产生更多的 ${ }^{1} \mathrm{O}_{2}$ 用于后续 PDT 过 程.

\section{5 体外 UCNPs-Ce6-TQ 对 A $\beta$ 聚集体的光氧化作用 研究}

硫黄素 $\mathrm{T}$ (Thioflavin T, ThT) 染料是 $\mathrm{A} \beta$ 聚集体 $\beta$-折 叠结构的经典荧光指示剂, $\mathrm{ThT}$ 荧光强度与富含 $\beta$ 折叠 结构的 $\mathrm{A} \beta$ 聚集体浓度呈正相关 ${ }^{[51-52]}$. 因此, 我们利用 ThT 苂光分析 UCNPs-Ce6-TQ 对 A $\beta$ 聚集体的解聚效果. 如图 4a 所示, 单独的近红外光 $\left(980 \mathrm{~nm}, 0.76 \mathrm{~W} / \mathrm{cm}^{2}\right)$ 照 射不会影响 $A \beta$ 聚集，在黑暗中加入 UCNPs-Ce6-TQ 观 察到 ThT 苂光强度有所下降, 而经过近红外光照射 UCNPs-Ce6-TQ 后 ThT 苂光强度显著下降，表明近红外 光照下 UCNPs-Ce6-TQ 对 $A \beta$ 聚集体有明显的解聚作用. 向 $20 \mu \mathrm{mol} / \mathrm{L} \mathrm{A} \beta$ 中加入 $100 \mu \mathrm{g} / \mathrm{mL}$ UCNPs-Ce6-TQ 材料,

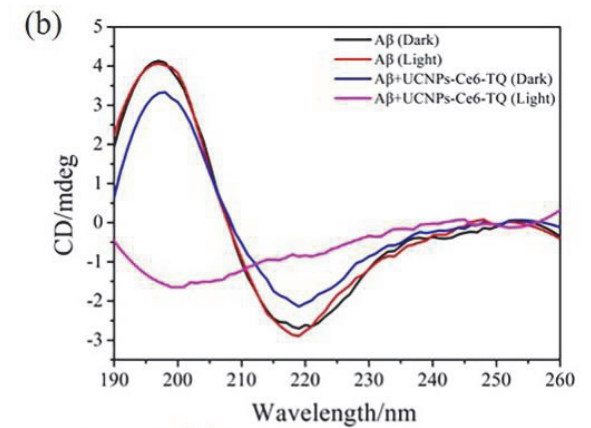

(c)
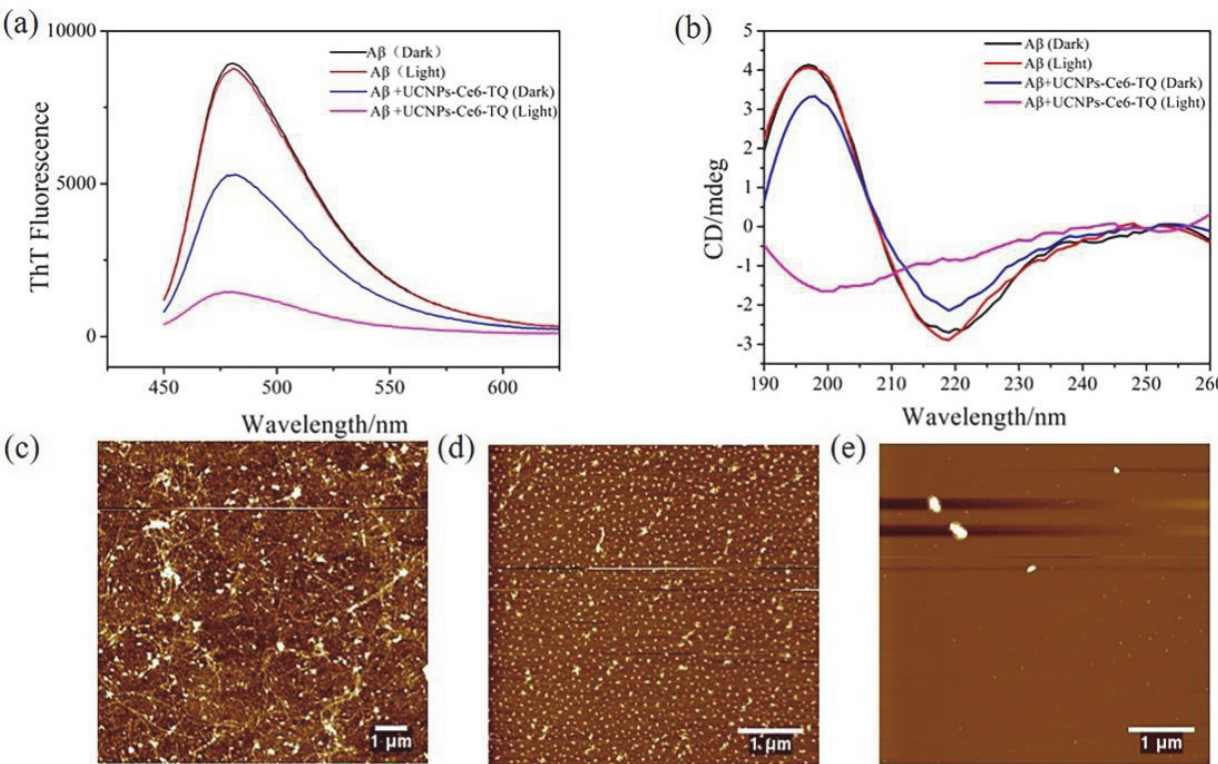

$\mathrm{A} \beta$ (Dark)

$\mathrm{A} \beta+\mathrm{UCNPs}-\mathrm{Ce} 6-\mathrm{TQ}$ (Dark)

A $\beta+$ UCNPs-Ce6-TQ

(Light)

(f)

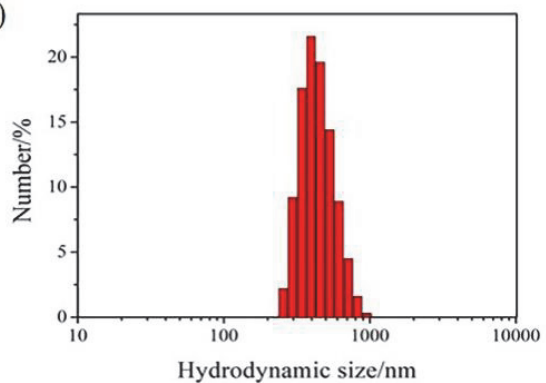

(g)

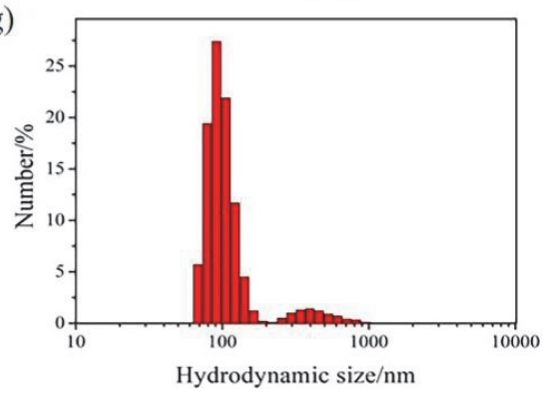

图 4 UCNPs-Ce6-TQ 在体外光氧化抑制 A $\beta$ 聚集体. (a) $480 \mathrm{~nm}$ 处 ThT 的苂光强度. (b) A $\beta$ 肽和与 UCNPs-Ce6-TQ 共孵育的 A $\beta$ 肽在黑暗或近红 外光照条件下的圆二色光谱. (c e e) 天然 $\mathrm{A} \beta$ 肽 $(20 \mu \mathrm{mol} / \mathrm{L}$ ) 和与 UCNPs-Ce6-TQ 共捊育的 $\mathrm{A} \beta$ 肽在不同条件下所得到的 $\mathrm{AFM}$ 图像. (f, g) 天然 $\mathrm{A} \beta$ 肽和与 UCNPs-Ce6-TQ 共孵育的 A $\beta$ 肽在近红外光照后的 DLS 粒径分布图

Figure 4 UCNPs-Ce6-TQ photooxidation inhibits A $\beta$ aggregates in vitro. (a) Fluorescence intensity of ThT at $480 \mathrm{~nm}$. (b) Circular dichroism spectrum of natural $A \beta$ peptides and $A \beta$ peptides co-incubated with UCNPs-Ce6-TQ under dark or near-infrared light conditions. (c $\sim$ e) AFM images of natural A $\beta$ peptides $(20 \mu \mathrm{mol} / \mathrm{L})$ and $\mathrm{A} \beta$ peptides co-incubated with UCNPs-Ce6-TQ in the dark or under near-infrared light conditions. DLS particle size distribution of (f) natural A $\beta$ peptide and (g) A $\beta$ peptide co-incubated with UCNPs-Ce6-TQ under near-infrared light irradiation 
并将其置于 $980 \mathrm{~nm}$ 激光下照射不同时间(如图 S12 所 示), ThT 的苂光强度随着辐射时间的增加而逐渐降低, 表明在 PDT 作用下, 随着活性氧的产生, $\mathrm{A} \beta$ 聚集体逐步 被降解. 在近红外光照 $20 \mathrm{~min}$ 后 $\mathrm{ThT}$ 苂光强度降低了约 $80 \%$, 证明了近红外光激发下 UCNPs-Ce6-TQ 对 ThT 的 苂光强度有显著影响, 对 $\mathrm{A} \beta$ 聚集体具有解聚作用.

我们进行了圆二色光谱分析, 以验证 UCNPsCe6-TQ 抑制 $A \beta$ 肽的 $\beta$-折叠结构的能力. 无规卷曲状态 的天然 $A \beta$ 肽通常在 $198 \mathrm{~nm}$ 处具有一个负峰, 但在形成 $\beta$-折叠结构后呈现出 $195 \mathrm{~nm}$ 的正峰和 $216 \mathrm{~nm}$ 的负峰 ${ }^{[53]}$. 如图 $4 b$ 所示, 孵育后 $A \beta$ 肽样品在 $195 \mathrm{~nm}$ 和 $216 \mathrm{~nm}$ 处 显示正峰和负峰, 表明富含 $\beta$-折叠结构的 $\mathrm{A} \beta$ 聚集体已 形成; 而近红外光 $\left(980 \mathrm{~nm}, 0.76 \mathrm{~W} / \mathrm{cm}^{2}\right)$ 照射对 $\mathrm{A} \beta$ 聚集 过程影响不明显, 加入 UCNPs-Ce6-TQ 再经近红外光照 射后曲线在 $195 \mathrm{~nm}$ 处峰值下降, 明显抑制了 $\mathrm{A} \beta$ 肽的 $\beta$ 折叠结构的出现, 说明 UCNPs-Ce6-TQ 具有光氧化解聚 $A \beta$ 聚集体的能力. UCNPs-Ce6-TQ 对 $A \beta$ 聚集过程的抑 制作用呈现剂量依赖性, 在相同光照的条件下随着 UCNPs-Ce6-TQ 浓度的增加, A $\beta$ 聚集体的 $\beta$-折叠含量减 少(图 S13b).

为了观察 $A \beta$ 聚集体的形貌变化, 我们对样品进行 了原子力显微镜(atomic force microscope, AFM)分析. 如图 $4 \mathrm{c} \sim 4 \mathrm{e}$ 所示, 天然的 $\mathrm{A} \beta$ 肽在聚集后可以观察到细 长的纤维, 当加入 UCNPs-Ce6-TQ 样品后共孵育后仍可 观察到 A $\beta$ 聚集体. 加入 UCNPs-Ce6-TQ 样品进行近红 外光 $\left(980 \mathrm{~nm}, 0.76 \mathrm{~W} / \mathrm{cm}^{2}\right)$ 照射后, 可以明显观察到一些 小碎片的形成, 而不是缠结的 $\mathrm{A} \beta$ 纤维状聚集体, 说明 我们构建的光氧化 UCNPs-Ce6-TQ 体系可以有效降解 $\mathrm{A} \beta$ 聚集体.

为了进一步证明上述结果, 我们利用 DLS 实验分 析了不同条件处理对 $A \beta$ 聚集体的尺寸影响. 如图 4f 所 示, 单独孵育 $20 \mu \mathrm{mol} / \mathrm{L}$ 的 $\mathrm{A} \beta$ 聚集体的水合动力学直径 为 $396.1 \mathrm{~nm}$. 当近红外光 $\left(980 \mathrm{~nm}, 0.76 \mathrm{~W} / \mathrm{cm}^{2}\right)$ 照射后, UCNPs-Ce6-TQ 降低了 A $\beta$ 聚集体的水合动力学直径至 $91.3 \mathrm{~nm}$ (图 4g). 该实验结果同样证明了 UCNPs-Ce6-TQ 在近红外光照射下解聚 $\mathrm{A} \beta$ 聚集体.

\section{6 纳米颗粒 BBB 渗透性考察}

BBB 主要由具有紧密连接的脑毛细血管内皮细胞

(a)

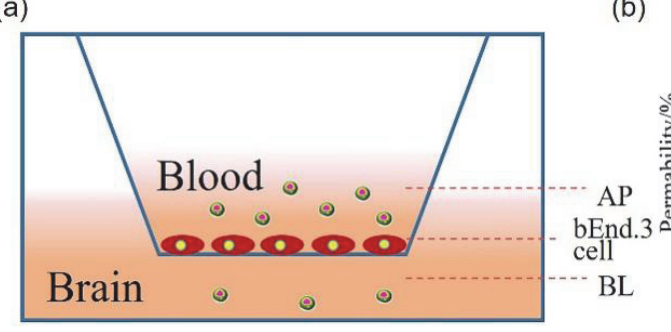

组成, 它仅允许某些特定的物质进入脑内, 目的在于保 护中枢神经系统免受神经毒性化合物的侵害 ${ }^{[54]}$. TGN 肽 可以靶向 BBB 随后通过转胞吞作用将纳米体系转运到 脑实质中. 因此, 我们将 TGN 肽链修饰在 UCNPsCe6-TQ 上使其具有渗透 BBB 的能力. 体外 Transwell 小室是对体内 $\mathrm{BBB}$ 情况进行模拟的一种简化模型. 如 图 5a 所示, 在模型上室(AP)孵育单层小鼠脑微血管内 皮细胞(bEnd.3 细胞)构建体外血脑屏障模型来考察纳米 体系穿过 BBB 的能力. 如图 S14 所示, 通过测量跨内皮 电阻值 (TEER) 对构建的 BBB 模型进行评估 ${ }^{[55]}$, 当 TEER 值高于 $150 \Omega \cdot \mathrm{cm}^{2}$ 时, 认为已成功构建了体外 BBB 模型. 加入 UCNPs-Ce6-TQ 在上室孵育 $18 \mathrm{~h}$ 后，通 过检测上室和下室中 UCNPs-Ce6-TQ 的浓度来分析纳 米体系穿过血脑屏障的能力(如图 S15), 对照组为未修 饰靶向肽链的 UCNPs-Ce6. 如图 5b 所示, 47.08\%的 UCNPs-Ce6-TQ 穿过 bEnd.3 细胞并进入下室(BL). 未经 TGN 修饰的 UCNPs-Ce6 几乎不能穿过体外 BBB 模型. 体外实验表明, UCNPs-Ce6-TQ 由于修饰了 TGN 肽而能 够有效穿过血脑屏障.

\subsection{UCNPs-Ce6-TQ 抑制 A 聚集体细胞毒性分析}

为了测定 UCNPs-Ce6-TQ 对 $A \beta$ 聚集体细胞毒性的 影响, 我们使用了 3-(4,5-二甲基-2-噻唑)-2,5-二苯基溴 化四氮唑噻唑蓝(MTT)分析法来评估大鼠嗜铬细胞瘤细 胞(PC12 细胞)的存活能力. 首先, 我们检测了 UCNPsCe6-TQ 对 PC12 细胞的细胞毒性, 确定了纳米体系的生 物相容性. 如图 6a 所示, UCNPs-Ce6-TQ 在 $0 \sim 0.5$ $\mathrm{mg} / \mathrm{mL}$ 的宽浓度范围内显示出 $80 \%$ 以上的细胞存活率， 证明 UCNPs-Ce6-TQ 具有良好的生物相容性. 之后，我 们评估了 UCNPs-Ce6-TQ 对 A $\beta$ 聚集体诱导细胞毒性的 缓解能力, 如图 $6 b$ 所示, 由于 $A \beta$ 寡聚体和原纤维诱导 的神经毒性, 观察到加入预先孵育形成的 $\mathrm{A} \beta$ 聚集体导 致 $\mathrm{PC} 12$ 细胞存活率降至 $40 \%$. 随后加入不同浓度 UCNPs-Ce6-TQ 样品与 A $\beta$ 聚集体共孵育后在黑暗的条 件下细胞存活率从 $40.81 \%$ 提高到 $47.46 \%$. 共同孵育 $\mathrm{A} \beta$ 聚集体与 UCNPs-Ce6-TQ 在近红外光 $(980 \mathrm{~nm}, 0.76$ $\mathrm{W} / \mathrm{cm}^{2}$ )照射不同时间后细胞存活率提高至 $70 \%$ 以上(图 $\mathrm{S} 16) . \mathrm{A} \beta$ 聚集体与不同浓度 UCNPs-Ce6-TQ 在近红外光 $\left(980 \mathrm{~nm}, 0.76 \mathrm{~W} / \mathrm{cm}^{2}\right.$ )照射 $25 \mathrm{~min}$, 每光照 $5 \mathrm{~min}$ 间隔冷

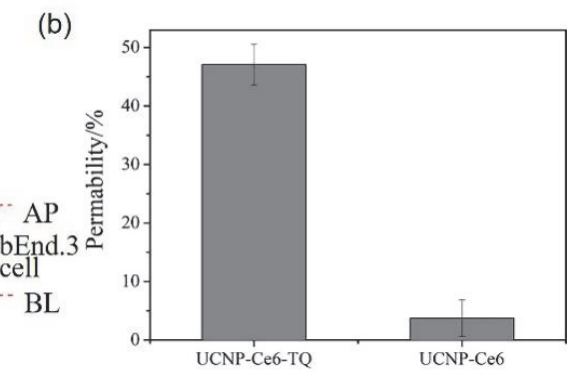

图 5 (a) 体外血脑屏障模型的示意图. (b) UCNPs-Ce6 和 UCNPs-Ce6-TQ 的体外 BBB 渗透性

Figure 5 (a) Scheme showing the design of the blood-brain barrier model. (b) In vitro BBB permeability of UCNPs-Ce6 and UCNPs-Ce6-TQ 

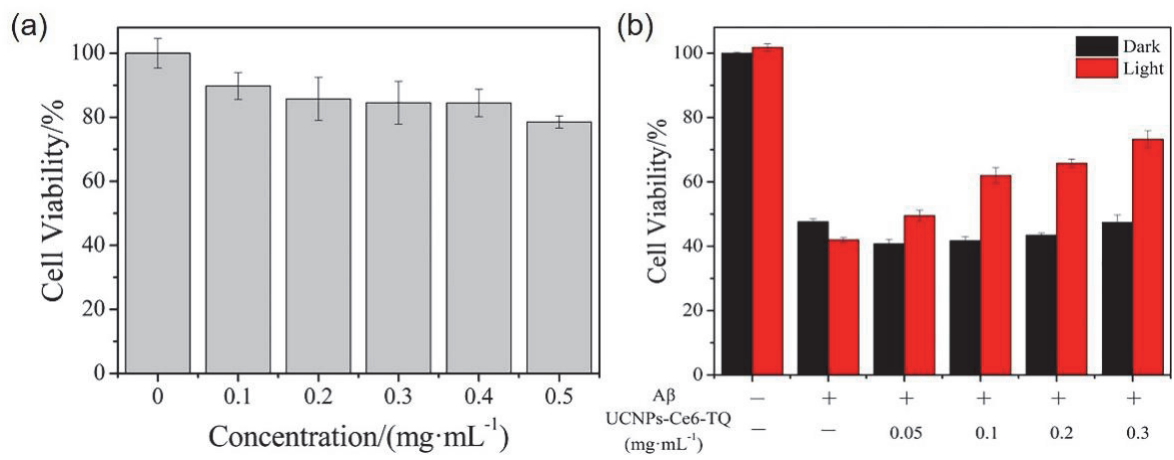

图 6 使用 MTT 分析评估 UCNPs-Ce6-TQ 的生物相容性和近红外光激发下 UCNPs-Ce6-TQ 对 A $\beta$ 肽诱导的细胞毒性的抑制作用. (a) 不同浓度 (0、 $0.1 、 0.2 、 0.3 、 0.4$ 和 $0.5 \mathrm{mg} / \mathrm{mL}$ ) UCNPs-Ce6-TQ 与 PC12 细胞捊育后细胞存活率分析. (b) 天然 A $\beta$ 肽与用不同浓度 UCNPs-Ce6-TQ 处理的 A $\beta$ 肽在黑暗或近红外光照条件下对 PC12 细胞活力的影响

Figure 6 MTT analysis to evaluate the biocompatibility of UCNPs-Ce6-TQ and the inhibition of A $\beta$ peptide-induced cytotoxicity under near-infrared light excitation. (a) Cell viability analysis of UCNPs-Ce6-TQ incubated with PC12 cells at different concentrations $(0,0.1,0.2,0.3,0.4 \mathrm{and} 0.5 \mathrm{mg} / \mathrm{mL})$. (b) Cell viability of PC12 incubated with natural $\mathrm{A} \beta$ peptides and $\mathrm{A} \beta$ peptides treated with different concentrations of UCNPs-Ce6-TQ under dark or near-infrared light irradiation conditions

却 $5 \mathrm{~min}$ 以防止过热(图 S17), $0.3 \mathrm{mg} / \mathrm{mL}$ UCNPs-Ce6-TQ 使得细胞存活率进一步提升至 73.26\%(图 6b), 表明在近 红外光照射下 UCNPs-Ce6-TQ 的光氧化作用可以显著 减弱 $A \beta$ 诱导的细胞毒性.

\section{3 结论}

总而言之, 我们成功构建了一种近红外光激发的双 靶向上转换纳米体系 UCNPs-Ce6-TQ 来抑制 $\mathrm{A} \beta$ 的聚集 过程, 从而缓解 $\mathrm{A} \beta$ 诱导的神经毒性. 设计的 UCNPs-Ce6-TQ 不仅具有良好的生物相容性，而且在近 红外光激发下可通过 LRET 将能量转移至光敏剂 Ce6, 使其跃迁至激发态后与周围的氧气分子作用产生单线 态氧 $\left({ }^{1} \mathrm{O}_{2}\right)$, 不可逆地氧化 $\mathrm{A} \beta$, 有效解聚富含 $\beta$-折叠的 $\mathrm{A} \beta$ 聚集体, 降低 $\mathrm{A} \beta$ 聚集体的神经毒性. 修饰了 TGN 和 QSH 双靶向肽链的 UCNPs-Ce6-TQ 可以实现有效穿透 血脑屏障并作用于 $\mathrm{A} \beta$. 该纳米体系显示出在大脑中抑 制 $\mathrm{A} \beta$ 的聚集治疗 $\mathrm{AD}$ 的潜力.

\section{4 实验部分}

\section{1 稀土油酸盐的合成}

参照文献中的方法具体合成步骤[56]如下：取 5 $\mathrm{mmol}$ 稀土氧化物 $\mathrm{Ln}_{2} \mathrm{O}_{3}$ 加入至 $20 \mathrm{~mL}$ 浓盐酸中, $70{ }^{\circ} \mathrm{C}$ 搅拌反应 $1 \sim 2 \mathrm{~h}$ 至溶液澄清透明后, 再升温到 $140{ }^{\circ} \mathrm{C}$ 将溶剂蒸干, 降温后得到 $\mathrm{LnCl}_{3}$ 固体. 将上述得到的 $\mathrm{LnCl}_{3}$ 与 $30 \mathrm{mmol}$ 油酸钠加入 $20 \mathrm{~mL}$ 乙醇, $15 \mathrm{~mL}$ 超纯水 和 $35 \mathrm{~mL}$ 己烷的混合溶剂中, 于 $70{ }^{\circ} \mathrm{C}$ 回流 $5.5 \mathrm{~h}$. 待反 应完成后, 将反应液转移至分液漏斗中分液, 留取上层 有机相, 将有机相用超纯水洗涤三次后, 把溶剂旋干,

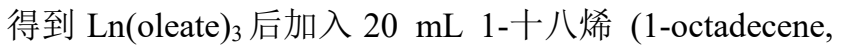
ODE) 和 $20 \mathrm{~mL}$ 油酸 (oleic acid, OA)于 $50{ }^{\circ} \mathrm{C}$ 溶解 $\operatorname{Ln}(\text { oleate })_{3}$.

\section{2 油酸修饰 UCNPs (OA-UCNPs)的合成}

根据逐层晶种生长法合成核-壳结构 UCNPs, 将 0.75 mmol Ln(oleate $)_{3}\left[n\left(\mathrm{Y}^{3+}\right): n\left(\mathrm{Yb}^{3+}\right): n\left(\mathrm{Er}^{3+}\right):\right.$ $\left.n\left(\mathrm{Gd}^{3+}\right): n\left(\mathrm{Tm}^{3+}\right)=67.8: 20: 2: 10: 0.2\right], \mathrm{NaF}(20$ $\mathrm{mmol}), 10 \mathrm{~mL} \mathrm{OA}$ 和 $10 \mathrm{~mL} \mathrm{ODE}$ 混合溶剂加入到三口烧 瓶中, 体系抽真空后, 在氩气保护环境下升温至 $120{ }^{\circ} \mathrm{C}$ 反应 $1 \mathrm{~h}$, 为了去除体系中的水和氧气. 随后升温在 $290{ }^{\circ} \mathrm{C}$ 下反应 $2 \mathrm{~h}$ 后, 再向体系中加入 $0.4 \mathrm{mmol}$ 溶于 8 $\mathrm{mL} \mathrm{OA}$ 和 ODE 混合溶剂中的 $\mathrm{Y}(\text { oleate })_{3}$, 继续反应 $1 \mathrm{~h}$ 后, 停止加热, 冷却至室温, 向收集的上层黄色清液中 加入等体积的无水乙醇, 离心收集白色沉淀. 用己烷溶 液将沉淀洗涤三次后, 并用体积比为 $1: 2$ 的已烷/乙醇 混合液沉淀 UCNPs, 最终产物分散于氯仿中保存, 获得 $\mathrm{NaYF}_{4}: \mathrm{Yb}, \mathrm{Er}, \mathrm{Gd}, \mathrm{Tm} @ \mathrm{NaYF}_{4}$.

\subsection{DSPE-PEG-MAL 修饰的 UCNPs 的合成}

将 $2 \mathrm{mg}$ OA-UCNPs 与 $4 \mathrm{mg}$ DSPE-PEG-MAL 在 $500 \mu \mathrm{L}$ 氯仿溶液中混合, 超声浴旋后, 使用温和的氮气 流吹干, 随后加入超纯水至 UCNPs 的浓度为 $1 \mathrm{mg} / \mathrm{mL}$ 超声分散溶解，接着在 $37{ }^{\circ} \mathrm{C}$ 孵育箱中反应 $40 \mathrm{~min}$, 将 溶液用 $13000 \mathrm{r} / \mathrm{min}$ 离心 $18 \mathrm{~min}$, 丢弃上清溶液, 继续水 洗一次. 最终分散于超纯水中备用, 浓度为 $1 \mathrm{mg} / \mathrm{mL}$ UCNPs-PEG.

\subsection{DSPE-PEG-MAL 包覆光敏剂纳米体系的构建}

向得到 UCNPs-PEG 溶液中缓慢加入不同体积的光 敏剂 Ce6 (1 mg/mL, DMSO), 浴旋 $1 \mathrm{~min}$. 接着于 $37{ }^{\circ} \mathrm{C}$ 孵育箱中反应 $4 \mathrm{~h}$, 设置 $13000 \mathrm{r} / \mathrm{min}$ 高速离心 $18 \mathrm{~min}$, 弃掉上层清液, 再水洗一次. 最终分散于超纯水中备用, 浓度为 $1 \mathrm{mg} / \mathrm{mL}$ UCNPs-Ce6.

\section{5 上转换荧光与光敏剂的负载量}

用三羟甲基氨基甲烷盐酸盐(Tris-HCl)缓冲溶液将 纳米体系按相同 UCNPs-Ce6 浓度进行稀释至 $1 \mathrm{mg} / \mathrm{mL}$, 
用 $980 \mathrm{~nm}$ 激光器激发检测上转换荧光, 并观察位于 655 $\mathrm{nm}$ 处的上转换发光强度猝灭. 通过紫外/可见分光光度 计测量离心后上清溶液中吸光度来计算游离的 Ce6 浓 度，从而计算出 UCNPs 表面的光敏剂负载量.

\section{6 双靶向 UCNPs-Ce6-TQ 纳米体系的合成}

通过 TGN (TGNYKALHOHNGC) 和 QSH (QSHYRHISPQVC)末端半胱氨酸上的琉基和 UCNP 表 面的马来酰亚胺基反应相连接. 称取适量 TGN 和 QSH 肽链溶解于灭菌的超纯水中, 分别配制成 $1 \mathrm{mg} / \mathrm{mL}$ $\mathrm{TGN}$ 和 $1 \mathrm{mg} / \mathrm{mL}$ QSH 水溶液. 按照 TGN 和 QSH 肽链 与 UCNPs 纳米颗粒质量浓度比为 $1: 5$ 的比例, 向 UCNPs-Ce6 溶液中同时加入 TGN 和 QSH 多肽水溶液, 在 $37{ }^{\circ} \mathrm{C}$ 孵育箱中低速震荡反应过夜后, 使用冷冻高速 离心机 $13000 \mathrm{r} / \mathrm{min}$ 离心 $18 \mathrm{~min}$ 进行后处理, 丢弃上清 溶液, 将沉淀继续水洗一次后分散在超纯水中, 制得终 浓度为 $1 \mathrm{mg} / \mathrm{mL}$ 的 UCNPs-Ce6-TQ 溶液.

\section{7 纳米体系中靶向肽链的负载量}

为了定量分析纳米体系中两条靶向肽链的量, 分别 使用 FITC 染料标记的 TGN 肽链和 TAMRA 染料标记的 QSH 肽链来替代 TGN 和 QSH, 根据 FITC-TGN 和 TAMRA-QSH 分别在 $477 \mathrm{~nm}$ 和 $557 \mathrm{~nm}$ 处的吸光度做出 标准曲线, 计算出肽链摩尔吸光系数. 通过测量离心处 理后上清溶液中 FITC-TGN 和 TAMRA-QSH 吸光度, 根 据相对应的摩尔吸光系数计算出游离的多肽量, 从而得 到负载于 UCNPs 表面肽链的量.

\section{8 活性氧的检测}

基于 $\mathrm{ABDA}$ 化学氧化的方法来评估纳米体系生成 ${ }^{1} \mathrm{O}_{2}$ 的能力. 水溶性 ABDA 在被 ${ }^{1} \mathrm{O}_{2}$ 氧化后表现出在 $433 \mathrm{~nm}$ 处苂光强度变化. 实验组为终浓度为 $8 \mu \mathrm{mol} / \mathrm{L}$ ABDA 和 $0.5 \mathrm{mg} / \mathrm{mL}$ UCNPs-Ce6 在 $\mathrm{pH} 7.4$ 的 Tris-HCl 缓冲体系中, 对照组是 $8 \mu \mathrm{mol} / \mathrm{L} \mathrm{ABDA}$ 溶液. 在有无 NIR 光照条件下, 于不同光照时间点通过荧光分光光度 计测量 $\mathrm{ABDA}$ 在 $433 \mathrm{~nm}$ 下苂光强度.

\section{$4.9 \mathrm{~A} \beta$ 聚集体的制备}

称取 $\mathrm{A} \beta_{42}$ 冻干粉 $1 \mathrm{mg}$ 置于离心管中, 加入 $1 \mathrm{~mL}$ 六 氟异丙醇(HFIP)复溶, 水浴超声 $10 \mathrm{~min}$, 室温静置 60 $\min$, 取 4 只无菌的离心管分装好. 随后用温和氮气流吹 干 HFIP, 在管壁上形成无色透明薄膜, 置于 $-20{ }^{\circ} \mathrm{C}$ 冰 箱中保存备用. 临用前, 取一支分装管, 向离心管中加 入 $11 \mu \mathrm{L}$ 二甲基亚砜(DMSO)超声溶解肽链, 再向其中 加 $539 \mu \mathrm{L}$ Tris- $\mathrm{HCl}(10 \mathrm{mmol} / \mathrm{L}, \mathrm{pH}=7.4)$ 浴旋均匀, 置 于 $37{ }^{\circ} \mathrm{C}$ 下孵育.

\subsection{ThT 检测}

将孵育的 $\mathrm{A} \beta_{42}$ 溶液和 $\mathrm{ThT}$ 溶液混合到缓冲液中, 配 置最终浓度为 $20 \mu \mathrm{mol} / \mathrm{L}$ 的 $\mathrm{A} \beta_{42}$ 溶液, $100 \mu \mathrm{g} / \mathrm{mL}$ UCNPs-Ce6-TQ 和 $20 \mu \mathrm{mol} / \mathrm{L}$ 的 ThT 溶液于 Tris- $\mathrm{HCl}$ (10 $\mathrm{mmol} / \mathrm{L}, \mathrm{pH}=7.4$ )缓冲体系中. 在近红外光 $980 \mathrm{~nm}$ 功率 为 $0.76 \mathrm{~W} / \mathrm{cm}^{2}$ 光照后, 通过苂光分光光度计测量 $\mathrm{ThT}$ 染 料在 $480 \mathrm{~nm}$ 的苂光强度来观察 $\mathrm{A} \beta_{42}$ 的聚集过程.

\subsection{1 圆二色谱分析}

使用圆二色谱仪来考察 $\mathrm{A} \beta_{42}$ 的二级结构, 配置好 $20 \mu \mathrm{mol} / \mathrm{L} \mathrm{A} \beta_{42} 、 20 \mu \mathrm{mol} / \mathrm{L} \mathrm{A} \beta_{42}$ 与 UCNPs-Ce6-TQ 共孵 育混合溶液, 在近红外光 $\left(980 \mathrm{~nm}, 0.76 \mathrm{~W} / \mathrm{cm}^{2}\right)$ 照射 30 $\min$ 及黑暗条件的处理后, 将所有待测溶液取样, 置于 光程 $1 \mathrm{~mm}$ 石英比色典中, 设置参数扫描带宽为 $1 \mathrm{~nm}$, 在氮气流室温条件下, 获得的 $190 \sim 260 \mathrm{~nm}$ 范围内的信 号, 减去 Milli-Q 的信号作为基线. 在所有测量中, 样品 体积为 $200 \mu \mathrm{L}$.

\subsection{AFM 检测}

取 $10 \mu \mathrm{L}$ 孵育过的 $\mathrm{A} \beta_{42}$ 溶液滴加到新鲜切割的云母 表面上, 然后使其吸附 $10 \mathrm{~min}$ 后, 用超纯水短时间漂洗 两次后, 并用温和的氮气流干燥. 通过使用 AFM 以敲 击模式获得 AFM 图像. 形态图像选用具有 $512 \times 512$ 像 素分辨率或 $1024 \times 1024$ 像素分辨率进行记录.

\subsection{DLS 分析}

在室温下使用 ZS ZEN3600 型激光粒度分析仪进行 粒径测量. 对于 DLS 测量, 将不同处理过的 $A \beta_{42}$ 样品 $(100 \mu \mathrm{mol} / \mathrm{L}, 200 \mu \mathrm{L})$ 稀释至 $1 \mathrm{~mL}$, 然后置于 DLS 的比 色血中. 一式三份进行测量.

\subsection{UCNPs-Ce6-TQ 的细胞毒性}

UCNPs-Ce6-TQ 的细胞毒性采用 MTT 方法检测. 首先将 PC12 细胞接种于 96 孔板中, 使用含有 $10 \%$ 胎牛 血清和 $1 \%$ 青霉素/链霉素的杜氏改良 Eagle 培养基 (Dulbecco's Modified Eagle Medium, DMEM), $37{ }^{\circ} \mathrm{C}$ 培 养 $24 \mathrm{~h}$. 随后加入含有不同浓度 UCNPs-Ce6-TQ 体系 ( $0 、 0.1 、 0.2 、 0.3 、 0.4 、 0.5 \mathrm{mg} / \mathrm{mL})$ 的新鲜培养基继续 培养 $24 \mathrm{~h}$. 除去含有材料的培养基, 并用含有 $20 \mu \mathrm{L}$ MTT 溶液 (5 mg/mL, 溶于磷酸盐缓冲溶液 (phosphate buffer saline, PBS)中)的新鲜培养基替换. 继续孵育 $4 \mathrm{~h}$ 后, 移除培养基, 每孔补加 $150 \mu \mathrm{L} \mathrm{DMSO}$ 震动溶解后, 使用酶标仪在 $490 \mathrm{~nm}$ 处测量所得的甲臜吸光度，根据 (实验组吸光度/对照组吸光度) $\times 100 \%$ 可计算细胞存活 率.

\subsection{5 建立体外 BBB 模型}

将 bEnd.3 细胞接种于 Transwell 12 孔板中, 使用含 有 $10 \%$ 胎牛血清和 $1 \%$ 青需素/链需素的 DMEM 培养基, 置于 $37{ }^{\circ} \mathrm{C}, 5 \% \mathrm{CO}_{2}$ 培养箱孵育. 每天换液一次, 在倒 置显微镜下观察细胞生长状况. 约生长 3 4 d 后观察细 胞基本融合后即对模型进行 TEER 实验，使用电阻仪测 量上室和下室的电阻值 $(\Omega)$. 有效电阻值 $\left(\Omega \cdot \mathrm{cm}^{2}\right)$ 计算方 式为 (实验组电阻值一对照组电阻值) $\times$ 膜面积. 当 TEER 值大于 $150 \Omega \bullet \mathrm{cm}^{2}$ 时, 然后将 $0.2 \mathrm{mg} / \mathrm{mL}$ 
UCNPs-Ce6-TQ 和 $0.2 \mathrm{mg} / \mathrm{mL}$ UCNPs-Ce6 加入上室中并 进一步孵育 $18 \mathrm{~h}$. 使用苂光分光光度计检测上室和下室 中 UCNPs-Ce6-TQ 和 UCNPs-Ce6 的浓度.

\subsection{UCNPs-Ce6-TQ 对 $A \beta$ 诱导的细胞毒性}

为了探究在 $A \beta_{42}$ 介导下用 UCNPs-Ce6-TQ 处理后 的细胞存活情况, 我们将 PC12 细胞接种在 96 孔板中, 培养箱中孵育 $24 \mathrm{~h}$ 后, 将 $10 \mu \mathrm{mol} / \mathrm{L}$ 天然 $\mathrm{A} \beta_{42}$ 肽, 在黑 暗或近红外光 $980 \mathrm{~nm}$, 功率密度为 $0.76 \mathrm{~W} / \mathrm{cm}^{2}$ 光照 25 $\mathrm{min}$, 每光照 $5 \mathrm{~min}$ 间隔冷却 $5 \mathrm{~min}$ 以防止过热, 与不同 浓度 $(0 、 0.1 、 0.2$ 和 $0.3 \mathrm{mg} / \mathrm{mL}$ ) 的 UCNPs-Ce6-TQ 共孵 育 $\mathrm{A} \beta_{42}$ 肽添加到细胞培养基中, 继续在培养箱中孵育

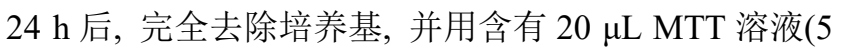
$\mathrm{mg} / \mathrm{mL}$, 溶于 PBS 中)的新鲜培养基替换. 将 96 孔板再 孵育 $4 \mathrm{~h}$. 向每个孔中加入 $150 \mu \mathrm{L}$ DMSO 溶解生成的紫 色甲臜. 使用酶标仪在 $490 \mathrm{~nm}$ 处测量其吸光度, 通过吸 光度计算细胞存活率. 其中不含细胞的孔为空白组, 每 个样品平行做 4 组, 所得结果取平均值.

\section{References}

[1] Alzheimer's association, Alzheimer's Dementia 2016, 12, 459.

[2] Savelieff, M. G.; Nam, G.; Kang, J.; Lee, H. J.; Lee, M.; Lim, M. H. Chem. Rev. 2019, 119, 1221.

[3] Iadanza, M. G.; Jackson, M. P.; Hewitt, E. W.; Ranson, N. A.; Radford, S. E. Nat. Rev. Mol. Cell Bio. 2018, 19, 755.

[4] Hardy, J.; Selkoe, D. J. Science 2002, 297, 353.

[5] Sun, H.; Liu, J.; Li, S.-L.; Zhou, L.-Y.; Wang, J.-W.; Liu, L.-B.; Lv, F.-T.; Gu, Q.; Hu, B.-Y.; Ma, Y.-G.; Wang, S. Angew. Chem. Int. Ed. 2019, 58, 5988.

[6] Fan, L.-Y.; Mao, C.-Y.; Hu, X.-C.; Zhang, S.; Yang, Z.-H.; Hu, Z.-H.; Sun, H.-F.; Fan, Y.; Dong, Y.-L.; Yang, J.; Shi, C.-H.; Xu, Y.-M. Front. Neurol. 2019, 10, 1312.

[7] De Strooper, B.; Vassar, R.; Golde, T. Nat. Rev. Neurol. 2010, 6, 99.

[8] Wilquet, V.; De Strooper, B. Curr. Opin. Neurobiol. 2004, 14, 582.

[9] Haass, C.; Selkoe, D. J. Nat. Rev. Mol. Cell Bio. 2007, 8, 101.

[10] Lee, S. J. C.; Nam, E.; Lee, H. J.; Savelieff, M. G.; Lim, M. H. Chem. Soc. Rev. 2017, 46, 310 .

[11] Ehrnhoefer, D. E.; Bieschke, J.; Boeddrich, A.; Herbst, M.; Masino, L.; Lurz, R.; Engemann, S.; Pastore, A.; Wanker, E. E. Nat. Struct. Mol. Biol. 2008, 15, 558.

[12] Taniguchi, A.; Sasaki, D.; Shiohara, A.; Iwatsubo, T.; Tomita, T.; Sohma, Y.; Kanai, M. Angew. Chem. Int. Ed. 2014, 53, 1382.

[13] Lee, B. I.; Lee, S.; Suh, Y. S.; Lee, J. S.; Kim, A.-k.; Kwon, O. Y.; Yu, K.; Park, C. B. Angew. Chem. Int. Ed. 2015, 54, 11472.

[14] Suh, J.-M.; Kim, G.; Kang, J.; Lim, M. H. Inorg. Chem. 2019, 58, 8.

[15] Guan, Y.-J.; Du, Z.; Gao, N.; Cao, Y.; Wang, X.-H.; Scott, P.; Song, H.-L.; Ren, J.-S.; Qu, X.-G. Sci. Adv. 2018, 4, eaao6718.

[16] Goyal, D.; Shuaib, S.; Mann, S.; Goyal, B. ACS Comb. Sci. 2017, $19,55$.

[17] Xiong, N.; Dong, X.-Y.; Zheng, J.; Liu, F.-F.; Sun, Y. ACS Appl. Mater. Inter. 2015, 7, 5650 .

[18] Niu, L.; Liu, L.; Xi, W.-H.; Han, Q.-S.; Li, Q.; Yu, Y.; Huang, Q.-X.; Qu, F.-Y.; Xu, M.; Li, Y.-B.; Du, H.-W.; Yang, R.; Cramer, J.; Gothelf, K. V.; Dong, M.-D.; Besenbacher, F.; Zeng, Q.-D.; Wang, C.; Wei, G-H..; Yang, Y.-L. ACS Nano 2016, 10, 4143.

[19] Han, Q.-S.; Cai, S.-F.; Yang, L.; Wang, X.-H.; Qi, C.; Yang, R.; Wang, C. ACS Appl. Mater. Inter. 2017, 9, 21116.

[20] Zhang, Z.-M.; Wang, J.; Song, Y.-X.; Wang, Z.-K.; Dong, M.-D.; Liu, L. Colloid. Surface. B 2019, 181, 341.

[21] Zhang, J.-Y.; Liu, J.-P.; Zhu, Y.-Y.; Xu, Z.-A.; Xu, J.; Wang, T.-T.; Yu, H.-J.; Zhang, W. Chem. Commun. 2016, 52, 12044.
[22] Ke, P. C.; Pilkington, E. H.; Sun, Y.; Javed, I.; Kakinen, A.; Peng, G.; Ding, F.; Davis, T. P. Adv. Mater. 2020, 32, 1901690.

[23] Yu, D.-Q.; Liu, C.; Zhang, H.-C.; Ren, J.-S.; Qu, X.-G. Chem. Sci. 2021, 12, 4963

[24] Du, Z.; Li, M.; Ren, J.-S.; Qu, X.-G. Acc. Chem. Res. 2021, 54, 2172.

[25] Furtado, D.; Björnmalm, M.; Ayton, S.; Bush, A. I.; Kempe, K.; Caruso, F. Adv. Mater. 2018, 30, 1801362.

[26] Ali, I. U.; Chen, X. ACS Nano 2015, 9, 9470.

[27] Yan, T.; Liu, Z.-H.; Song, X.-Y.; Zhang, S.-S. Acta Chim. Sinica 2020, 78, 657 (in Chinese). (问涛, 刘振华, 宋昕玥, 张书圣, 化学 学报, 2020, 78, 657.)

[28] Li, M.-L.; Peng, X.-J. Acta Chim. Sinica 2016, 74, 959 (in Chinese). (李明乐, 彭孝军, 化学学报, 2016, 74, 959.)

[29] Liu, W.; Dong, X.-Y.; Liu, Y.; Sun, Y. Acta Biomater. 2021, 123, 93.

[30] Lee, B. I.; Chung, Y. J.; Park, C. B. Biomaterials 2019, 190-191, 121.

[31] Tang, Y.-F.; Pei, F.; Lu, X.-M.; Fan, Q.-L.; Huang, W. Adv. Opt. Mater. 2019, 7, 1900917.

[32] Liu, H.-W.; Zhu, L.-M.; Lou, X.-F.; Yuan, L.; Zhang, X.-B. Acto Chim. Sinica 2020, 78, 1240 (in Chinese). (刘红文, 朱隆民, 娄霄 峰, 袁林, 张晓兵, 化学学报, 2020, 78, 1240.)

[33] Yang, Y.; Liu, H.-L.; Han, M.-J.; Sun, B.-B.; Li, J.-B. Angew. Chem. Int. Ed. 2016, 55, 13538.

[34] Dong, H.; Du, S.-R.; Zheng, X.-Y.; Lyu, G.-M.; Sun, L.-D.; Li, L.-D.; Zhang, P.-Z.; Zhang, C.; Yan, C.-H. Chem. Rev. 2015, 115, 10725 .

[35] Chen, G.-Y.; Qiu, H.-L.; Prasad, P. N.; Chen, X.-Y. Chem. Rev. 2014, $114,5161$.

[36] Zhou, J.; Liu, Z.; Li, F.-Y. Chem. Soc. Rev. 2012, 41, 1323.

[37] Zheng, W.; Huang, P.; Tu, D.-T.; Ma, E.; Zhu, H.-M.; Chen, X.-Y. Chem. Soc. Rev. 2015, 44, 1379.

[38] Wang, P.-P.; Liang, T.; Zuo, M.-M.; Li, Z.; Liu, Z.-H. Acta Chim Sinica 2020, 78, 797 (in Chinese). (王培培, 梁涛, 左苗苗, 李贞, 刘志洪, 化学学报, 2020, 78, 797.)

[39] Idris, N. M.; Jayakumar, M. K. G.; Bansal, A.; Zhang, Y. Chem. Soc. Rev. 2015, 44, 1449.

[40] Yang, D.-M.; Ma, P. A.; Hou, Z.-Y.; Cheng, Z.-Y.; Li, C.-X.; Lin, J. Chem. Soc. Rev. 2015, 44, 1416.

[41] Hao, C.-L.; Wu, X.-L.; Sun, M.-Z.; Zhang, H.-Y.; Yuan, A.-M.; Xu, L.-G.; Xu, C.-L.; Kuang, H. J. Am. Chem. Soc. 2019, 141, 19373.

[42] Zhu, X.-J.; Li, J.-C.; Qiu, X.-C.; Liu, Y.; Feng, W.; Li, F.-Y. Nat. Commun. 2018, 9, 2176.

[43] Zhao, J.; Chu, H.-Q.; Zhao, Y.; Lu, Y.; Li, L.-L. J. Am. Chem. Soc. 2019, 141, 7056

[44] Xu, J.; Xu, L.-G.; Wang, C.-Y.; Yang, R.; Zhuang, Q.; Han, X.; Dong, Z.-L.; Zhu, W.-W.; Peng, R.; Liu, Z. ACS Nano 2017, 11, 4463 .

[45] Zhou, Y.-Q.; Peng, Z.-L.; Seven, E. S.; Leblanc, R. M. J. Control. Release 2018, 270, 290.

[46] Li, J.-W.; Feng, L.; Fan, L.; Zha, Y.; Guo, L-R.; Zhang, Q.-Z.; Chen, J.; Pang, Z.-Q.; Wang, Y.-C.; Jiang, X.-G.; Yang, V. C.; Wen, L.-P. Biomaterials 2011, 32, 4943.

[47] Yang, L.-C.; Sun, J.; Xie, W.-J.; Liu, Y.-N.; Liu, J. J. Mater. Chem. B 2017, 5, 5954.

[48] Wiesehan, K.; Buder, K.; Linke, R. P.; Patt, S.; Stoldt, M.; Unger, E.; Schmitt, B.; Bucci, E.; Willbold, D. ChemBioChem 2003, 4, 748.

[49] Zhang, C.; Zheng, X.-Y.; Wan, X.; Shao, X.-Y.; Liu, Q.-F.; Zhang, Z.-M.; Zhang, Q.-Z. J. Control. Release 2014, 192, 317.

[50] Zhang, C.; Wan, X.; Zheng, X.-Y.; Shao, X.-Y.; Liu, Q.-F.; Zhang, Q.-Z.; Qian, Y. Biomaterials 2014, 35, 456.

[51] Biancalana, M.; Koide, S. BBA-Proteins Proteomics 2010, 1804, 1405.

[52] Younan, N. D.; Viles, J. H. Biochemistry 2015, 54, 4297.

[53] Bartolini, M.; Bertucci, C.; Bolognesi, M. L.; Cavalli, A.; Melchiorre, C.; Andrisano, V. ChemBioChem 2007, 8, 2152.

[54] Abbott, N. J.; Patabendige, A. A.; Dolman, D. E.; Yusof, S. R.; Begley, D. J. Neurobiol. Dis. 2010, 37, 13.

[55] Srinivasan, B.; Kolli, A. R.; Esch, M. B.; Abaci, H. E.; Shuler, M. L.; Hickman, J. J. J. Lab. Autom. 2015, 20, 107.

[56] Wei, Y.; Lu, F.-Q.; Zhang, X.-R.; Chen, D.-P. Chem. Mater. 2006, 18,5733 